\title{
Kaposiform hemangioendothelioma with distant lymphangiomatosis without an association to Kasabach-Merritt-Syndrome in a female adult!
}

\author{
Claudia S Vetter-Kauczok' \\ Philipp Ströbel ${ }^{2}$ \\ Eva B Bröcker' \\ Jürgen C Becker' \\ 'Department of Dermatology, Julius- \\ Maximilians-University Wuerzburg, \\ Wuerzburg, Germany; ${ }^{2}$ Department of \\ Pathology, Ruprecht-Karls-University \\ Mannheim, Mannheim, Germany
}

\begin{abstract}
Kaposiform hemangioendothelioma (KHE) is a locally aggressive vascular tumor which usually occurs in infants. Clinically it appears as ill-defined red to purple indurated plaque. KHE is commonly associated with Kasabach-Merritt syndrome (KMS) and lymphangiomatosis. Microscopically, the tumor is composed of infiltrating lobulated nodules with slitlike or crescentic vessels which are poorly canalized and lined by spindle shaped endothelial cells. We report a 36-year old female who developed a reddish tumor on the chest. Histological examination revealed a KHE, which was clinically not associated with thrombocytopenia or bleeding complications, but lymphangiomatosis at the right submandibular region. The association of KHE in a female adult with lymphangioma rather than KMS in this case supports the hypothesis that such an association may represent a benign subform of this disease in an adult and excision seems to be curative.
\end{abstract}

Keywords: Kasabach-Merritt-Syndrom, Kaposiform hemangioendothelioma, lymphangiomatosis

\section{Background}

The term 'hemangioendothelioma' (HE) was introduced by Mallory in 1908 to include all 'tumors arising from blood vessel endothelium' (Mallory 1908). Notably, this name was established irrespective of the clinical behavior of the tumor. Forty years later, Stout and colleagues (1943) described the microscopic appearances of malignant tumors of blood vessels and linked the term HE to malignant behavior. This notion was put into perspective by Enzinger and Zhang (1988), who described HE as vascular tumors of intermediate, borderline, or low grade malignancy. Since then, this term has been used to designate various groups of vascular tumors; eg, kaposiform hemangioendothelioma (KHE) for a locally aggressive form. This rare vascular tumor, predominantly occurs in infancy and early childhood and is associated with lymphatic vessel proliferation as well as Kasabach-Merritt syndrome (KMS) (Kasabach and Merritt 1940; Niedt et al 1989; Zukerberg et al 1993; Enjolras and Mulliken 1997; Sarkar et al 1997; Enjolras et al 2000). The 'borderline' malignant behavior of KHE is enriched by locally aggressive growth (Tsang and Chan 1991), but distant metastatic spread is absent and could be cured by early and radical excision. Otherwise, KHE causes significant morbidity and mortality compression and invasion of surrounding structures, disease-associated mortality may reach $12 \%$ (el Dessouky et al 1988).

\section{Case presentation}

In January 2005, a 36-year old patient perceived for the first time a reddish $7 \times 4 \mathrm{~mm}$ tumor on her right chest. She experienced neither itching nor bleeding from the lesion and no systemic or topical treatment had been applied. Her history as to personal 
or familial hemorrhage, thrombocytopenia or mucosal bleeding was inconspicuous. Thorough inspection of the entire integument revealed a few pigmented melanocytic lesions, which displayed no abnormalities upon clinical examination or epiluminescence microscopy. The only additional finding was a $2 \times 2,5 \mathrm{~mm}$ reddish macule with an indistinct border in the right submandibular region.

The tumor on the chest was excised since it was suspected to be an amelanotic melanoma. Histological examination revealed a dermally situated indistinctly demarcated mesenchymal process containing many capillary canaliculi lined by spindled epithelial cells. The tumor cells were characterized by slightly enlarged, ovalshaped, and occasional prominent nuclei. A few mitotic figures were present within these cells. Dilated hyperplastic lymphatic channels (ie, lymphangiomatosis) were absent. Immunohistochemistry revealed a strong expression of
CD31 (Figure 1A), CD34 (Figure 1B) and FLI1 - as nuclear marker for endothelial differentiation - whereas actin and HHV8 (Figure 1C) were not detectable. The patient was HIV negative. These findings were consistent with the diagnosis of KHE and so it could be cured by a complete excision. Unfortunately a magnetic resonance imaging (MRI) was not done before excision to evaluate the extension of KHE because of the different tentative diagnosis.

A subsequently performed second excision ensured a safety margin of $5 \mathrm{~mm}$. At the same time the macula at the right submandibular region was removed. Histologically, multiple dilated vessels in the upper dermis were visible. A few of the vessels contained erythrocytes in their lumina while the majority of the vessels only held lymph and stained positive for D2-40 (Figure 1D). The clinical follow up of the patient to date was without pathological findings.
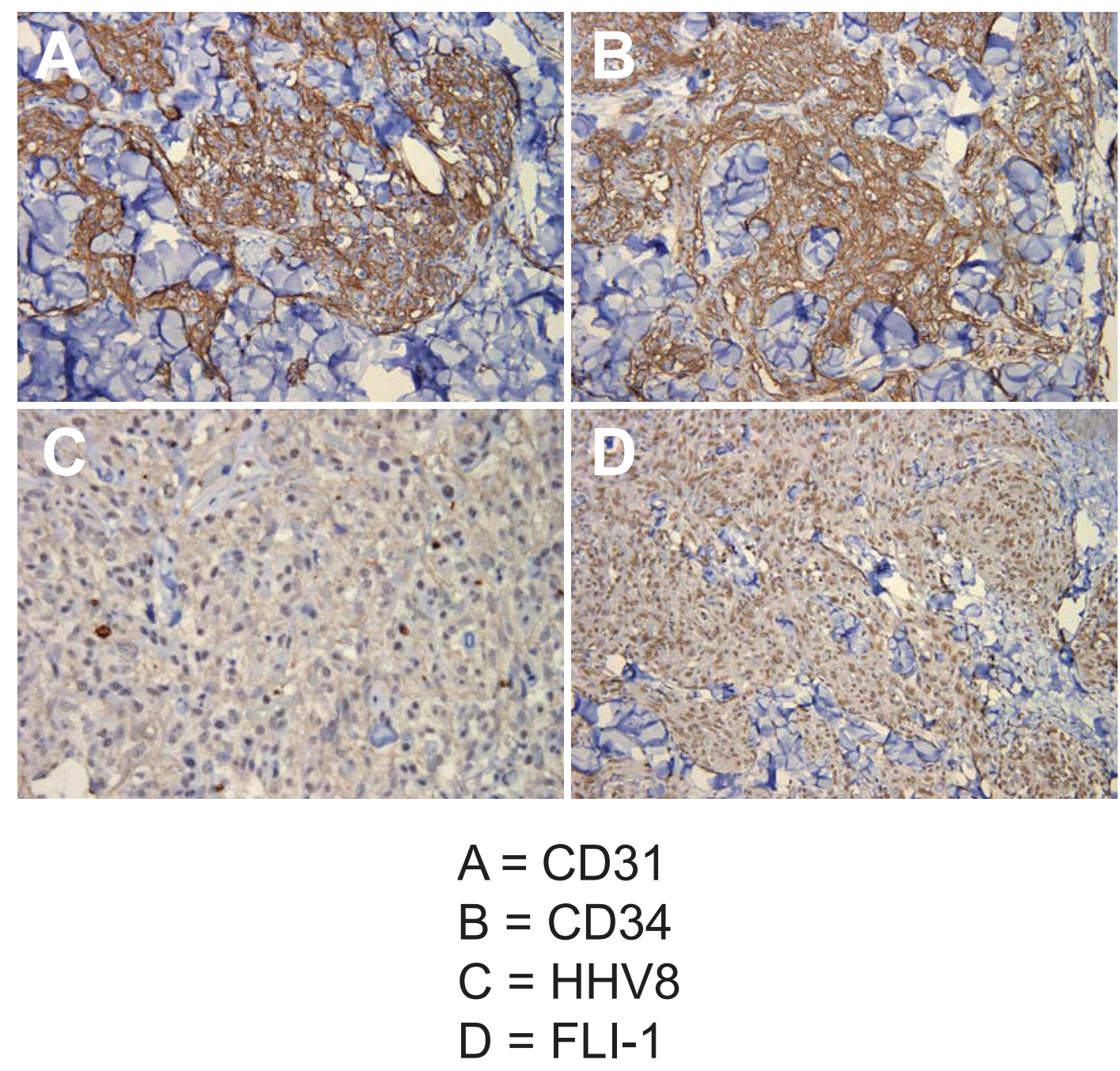

Figure I Immunohistology: immunohistochemical stainings for CD3I (A), CD34 (B), HHV8 (C), and D2-40 (D) of the chest tumor (immunoperoxidase, original magnification: A-C 40×, D 20×). 


\section{Conclusion}

Clinical and histological differential diagnosis of KHE in adults includes Kaposi sarcoma, amelanotic melanoma, spindle cell hemangioendothelioma, tufted angioma, cellular capillary hemangioma, and angiosarcoma (Fletcher et al 1991). Hence, the diagnosis critically depends on histopathological and immunohistochemical examination. Even if this tumor metastasizes only in rare cases (Lai et al 1991; Bhutto et al 1995), it still has a systemic impact; ie, distant lymphatic abnormalities. In fact, the extent of these lymphatic abnormalities is more striking than previously noted (Zukerberg et al 1993). While the majority of KHE exhibit such changes in the immediate vicinity, lymphatic abnormalities in the lung and mediastinum have also been reported, particularly in young children (Enjolras and Mulliken 1997). Notably, one patient even died of this lymphatic proliferation (Lyons et al 2004). These lymphatic abnormalities seem to be evoked by systemic factors. Hypothetically, the tumor may produce lymphatic endothelial growth factors which incite proliferation of adjacent lymphatics; if the production of theses factors reaches sufficient amounts, systemic effects on susceptible vessels may occur (Wigle et al 2002). The importance of tissue susceptibility is exemplified by the here reported findings, ie, no lymphangiomatosis in the tumor stroma itself or its close vicinity, but in some distance.

Complete surgical excision is the most effective treatment of small KHE lesions (Drolet et al 2001; George et al 2002). However, tumor site or localization may prevent this treatment option. Moreover, an active intervention is required when KMS is present. To this end, therapy of KMS has proven to be a therapeutic challenge and may need multimodality approach including steroids, cytotoxic agents and interferon $\alpha$ (Hu et al 1998).

In the presented case, neither the size of the tumor posed a problem for a surgical intervention nor did a coagulopathia require additional systemic measures. This report therefore supports the notions that (i) small KHE can be cured by complete excision and (ii) younger patients with KHE are more prone to KMS than adults (Shim 1968; Lyons et al 2004). In this regard, Zukerberg and colleagues (1993) reported two cases of KHE associated with lymphangiomatosis which also did not show any signs of KMS and (iii) larger vascular tumors are more frequently associated with thrombocytopenia than small lesions. From this observation, it was concluded that lymphangiomatosis may actually be associated with noncoagulopathic tumors. One hypothesis is that $\mathrm{KH}$ begins as a lymphatic malformation onto which a vascular component is engrafted. This idea is supported by the occasional cases reported in the skin in which the lymphatic component overshadows the vascular component. A more elegant hypothesis is that KHE actually produces lymphatic endothelial growth factors, which incite proliferation of lymphatics. This hypothesis, although in concordance with our present observation, awaits confirmation by large series of cases.

KHE has been believed to occur almost exclusively in infants and young children, however, an increasing number of cases in adults have been reported (Mentzel et al 1997; Mac-Moune et al 2001; Cooper et al 2002). Most of the adult patients showed KHE without an association with KMS but local or distant lymphangiomatosis.

Our present report of a 36-year-old patient suffering from KHE without KMS but distant lymphangiomatosis adds to this list. Hence, KHE in adults not associated with KMS but local or distant lymphangiomatosis may be regarded as a subform with favorable prognosis and can be cured by radical excision.

\section{Disclosure}

This report was funded by the University of Wuerzburg. The authors have no conflict of interest to disclose.

\section{References}

Bhutto AM, Uehara K, Takamiyagi A, et al. 1995. Cutaneous malignant hemangioendothelioma: clinical and histopathological observations of nine patients and a review of the literature. J Dermatol, 22:253-61.

Cooper JG, Edwards SL, Holmes JD. 2002. Kaposiform haemangioendothelioma: case report and review of the literature. Br J Plast Surg, 55:163-5

Drolet BA, Scott LA, Esterly NB, et al. 2001. Early surgical intervention in a patient with Kasabach-Merritt phenomenon. J Pediatr, 138:756-8.

el Dessouky M, Azmy AF, Raine PA, et al. 1988. Kasabach-Merritt syndrome. J Pediatr Surg, 23:109-111.

Enjolras O, Mulliken JB. 1997. Vascular tumors and vascular malformations (new issues). Adv Dermatol, 13:375-423.

Enjolras O, Mulliken JB, Wassef M, et al. 2000. Residual lesions after Kasabach-Merritt phenomenon in 41 patients. J Am Acad Dermatol, 42:225-35.

Enzinger FM, Zhang RY. 1988. Plexiform fibrohistiocytic tumor presenting in children and young adults. An analysis of 65 cases. Am J Surg Pathol, 12:818-26.

Fletcher CD, Beham A, Schmid C. 1991. Spindle cell haemangioendothelioma: a clinicopathological and immunohistochemical study indicative of a non-neoplastic lesion. Histopathology, 18:291-301.

George M, Singhal V, Sharma V, et al. 2002. Successful surgical excision of a complex vascular lesion in an infant with Kasabach-Merritt syndrome. Pediatr Dermatol, 19:340-4.

Hu B, Lachman R, Phillips J, et al. 1998. Kasabach-Merritt syndromeassociated kaposiform hemangioendothelioma successfully treated with cyclophosphamide, vincristine, and actinomycin D. J Pediatr Hematol Oncol, 20:567-9.

Kasabach HH, Merritt KK. 1940. Capillary hemangioma with extensive purpura. Am J Dis Child, 59:1063-70. 
Lai FM, Allen PW, Yuen PM, et al. 1991. Locally metastasizing vascular tumor. Spindle cell, epithelioid, or unclassified hemangioendothelioma? Am J Clin Pathol, 96:660-3.

Lyons LL, North PE, Mac-Moune LF, et al. 2004. Kaposiform hemangioendothelioma: a study of 33 cases emphasizing its pathologic, immunophenotypic, and biologic uniqueness from juvenile hemangioma. Am J Surg Pathol, 28:559-68.

Mac-Moune LF, To KF, Choi PC, et al. 2001. Kaposiform hemangioendothelioma: five patients with cutaneous lesion and long follow-up. Mod Pathol, 14:1087-92.

Mallory FB. 1908. The results of the application of special histological methods to the study of tumors. J Exp Med, 10:575-93.

Mentzel T, Mazzoleni G, Dei Tos AP et al. 1997. Kaposiform hemangioendothelioma in adults. Clinicopathologic and immunohistochemical analysis of three cases. Am J Clin Pathol, 108:450-5.

Niedt GW, Greco MA, Wieczorek R, et al. 1989. Hemangioma with Kaposi's sarcoma-like features: report of two cases. Pediatr Pathol, 9:567-75.

Sarkar M, Mulliken JB, Kozakewich HP, et al. 1997. Thrombocytopenic coagulopathy (Kasabach-Merritt phenomenon) is associated with Kaposiform hemangioendothelioma and not with common infantile hemangioma. Plast Reconstr Surg, 100:1377-86.
Shim WK. 1968. Hemangiomas of infancy complicated by thrombocytopenia. Am J Surg, 116:896-906.

Stout AP. 1943. Hemangioendothelioma: a tumor of blood vessels featuring. Ann Surg, 118:445-64.

Tsang WY, Chan JK. 1991. Kaposi-like infantile hemangioendothelioma. A distinctive vascular neoplasm of the retroperitoneum. Am J Surg Pathol, 15:982-9.

Wigle JT, Harvey N, Detmar M, et al. 2002. An essential role for Prox1 in the induction of the lymphatic endothelial cell phenotype. EMBO $J, 21: 1505-13$.

Zukerberg LR, Nickoloff BJ, Weiss SW. 1993. Kaposiform hemangioendothelioma of infancy and childhood. An aggressive neoplasm associated with Kasabach-Merritt syndrome and lymphangiomatosis. Am J Surg Pathol, 17:321-8. 